\title{
Influence of phosphorus and nitrogen co- doping of activated carbon from littered cigarette filters for adsorption of methylene blue dye from wastewater
}

Samantha Macchi ${ }^{1}$, Zane Alsebai ${ }^{2}$, Fumiya Watanabe ${ }^{3}$, Arooba llyas ${ }^{1}$, Shiraz Atif ${ }^{1}$, Tito Viswanathan ${ }^{1}$ and Noureen Siraj $^{1 *}$ D

\begin{abstract}
Global access to sanitary water is of utmost importance to human health. Presently, textile dye water pollution and cigarette pollution are both plaguing the environment. Herein, waste cigarette filters (CFs) are converted into useful carbon-based adsorbent materials via a facile, microwave-assisted carbonization procedure. The CFs are activated and co-doped with phosphorus and nitrogen simultaneously to enhance their surface characteristics and adsorbent capability by introducing chemisorptive binding sites to the surface. The doped carbonized CF (DCCF) and undoped carbonized CF (CCF) adsorbents are characterized physically to examine their surface area, elemental composition, and surface charge properties. The maximum adsorption capacity of synthesized adsorbents was determined via batch adsorption experiments and Langmuir modelling. Additionally, the influence of different parameters on the adsorption process was studied by varying the adsorption conditions such as adsorbent dosage, initial concentration, contact time, temperature, and pH. The DCCF adsorbent showed a maximum adsorption capacity of $303 \mathrm{mg} \mathrm{g}^{-1}$. Adsorption of both adsorbents fit best to Langmuir model and pseudo-second order kinetics, indicating chemisorptive mechanism. Both adsorbents showed endothermic adsorption process which is indicated by increasing adsorption capacity with increased temperatures. DCCF exhibited greater adsorption capability than CCF at all temperatures from 25 to $55^{\circ} \mathrm{C}$. The $\mathrm{pH}$ of the solution significantly affected the adsorption capacity of CCF while DCCF adsorption is favorable at a wide $\mathrm{pH}$ range due to low value of the adsorbent's point of zero charge. Reusability results showed that both adsorbents can be used over several cycles for removal of dye. Thus, results conclude that the waste DCCF-based adsorbent does not only show a profound potential as a sustainable solution to combat textile dye water pollution but also addresses the valuable use of the CF pollution simultaneously. This approach, which can target two major pollutants, is attractive due to its ease of preparation, negligible cost, and versatility in application.
\end{abstract}

Keywords: Doped carbon, Dye adsorption, Water purification, Green chemistry, Microwave, Cigarette, Methylene blue

\footnotetext{
* Correspondence: nxsiraj@ualr.edu

'Department of Chemistry, University of Arkansas, Little Rock 72204, USA

Full list of author information is available at the end of the article
}

(C) The Author(s). 2021 Open Access This article is licensed under a Creative Commons Attribution 4.0 International License, which permits use, sharing, adaptation, distribution and reproduction in any medium or format, as long as you give appropriate credit to the original author(s) and the source, provide a link to the Creative Commons licence, and indicate if changes were made. The images or other third party material in this article are included in the article's Creative Commons licence, unless indicated otherwise in a credit line to the material. If material is not included in the article's Creative Commons licence and your intended use is not permitted by statutory regulation or exceeds the permitted use, you will need to obtain permission directly from the copyright holder. To view a copy of this licence, visit http://creativecommons.org/licenses/by/4.0/. 


\section{Introduction}

Water pollution is an enormous problem worldwide, with the textile industry contributing to the overall pollution of water in a major way. Textile mills account for around $20 \%$ of all industrial water pollution; an approximate of 20,000 different chemicals and dyes contaminate water [1]. These synthetic dyes are incredibly stable, and thus are resistant to degradation under high temperatures, light exposure, and chemical treatment. Moreover, many of these dyes cannot be biodegraded under aerobic conditions and are highly soluble in water with visibility to the naked eye at minute concentrations (down to 1 ppm) [2]. As a result of their immense stability, current large-scale wastewater treatments are ineffective for dye removal, high in cost, or both, causing a significant portion of industrial dyes to be released into the environment.

Several prominent chemical and physical methods are used currently for textile dye removal from effluents, such as coagulation-flocculation, aerobic degradation, and adsorption [3]. Adsorption is a common choice to remove dye from solution as it is a relatively simple and inexpensive method [4, 5]. Recently, many researchers are examining the potential of waste resources for preparing activated carbons. A variety of precursors have been investigated such as tea [6], chitosan [7], and citrus peels [8]. There are also an increasing number of reports using heteroatoms such as nitrogen [9-11], phosphorus [12], or sulfur [13] doped activated carbon materials, to achieve enhanced adsorption. These heteroatoms produce various functional groups at the adsorbent's surface that aid in binding dye molecules to the surface of adsorbent via alteration of surface polarity and acidity [14]. Many materials have shown promising results using dual or co-doping with two different elements $[15,16]$. In this work, cigarette filter (CF) waste will be explored as a carbon precursor for synthesis of co-doped carbon material.

Cigarette waste contributes to the largest amount of plastic pollution around the world [17]. Most CFs, the part of the cigarette that remains after smoking, are tossed onto the ground, leading to immense ecological pollution. CFs are composed mainly of plastic, viz. cellulose acetate, which is not readily biodegradable [18]. Additionally, CFs contain toxic metals that can be leeched into soil and water, causing direct harm to plants and animals [19]. Due to the posed ecological threat of the litter, new methods of reducing cigarette pollution are needed. Since CFs are comprised mostly of cellulose acetate, a carbon-based polymer, these waste products can easily be utilized as carbon precursors for production of activated carbons [20-22].

This work aims to convert used CFs into useful carbon adsorbents via inexpensive and facile microwave-assisted approach. The phosphorus and nitrogen heteroatomdoped carbon contains functional groups which may have a synergistic effect on the adsorption capacity. Both undoped and doped carbons from CFs are characterized in detail. Methylene Blue (MB) dye is used to investigate the adsorption characteristics of the newly developed phosphorus and nitrogen co-doped carbon from cigarette filter (DCCF) and undoped carbonized cigarette filter (CCF). To the best of our knowledge, no work has reported the use of this one-step microwave-assisted method for producing DCCF and its use as an adsorbent.

\section{Materials and methods Chemicals}

Waste CFs were collected from the University of Arkansas at Little Rock campus and rinsed with deionized (DI) water to remove any external residues like dust, and they were dried in air prior to their use. The paper casing was removed prior to carbonization. Ammonium polyphosphate (APP, avg. mw: 97) was a gift from JLS Chemicals. Sodium nitrate $\left(\mathrm{NaNO}_{3}\right)$ was purchased from ACROS. MB dye was purchased from Sigma Aldrich. Elga model PURELAB ultra water-filtration system was used to collect DI water $(18.2 \mathrm{M} \Omega \mathrm{cm})$. Reagent grade hydrochloric acid $(\mathrm{HCl})$, sodium hydroxide $(\mathrm{NaOH})$, and ethanol were purchased from VWR and diluted to 0.01 $\mathrm{M}$ solutions to adjust $\mathrm{pH}$.

\section{Adsorbent synthesis}

Waste CFs were collected from receptacles located around University of Arkansas at Little Rock campus and carbonized through a facile, low-cost, microwaveassisted method described previously [23]. For synthesis of DCCF, the CFs were weighed and combined with APP in a mass ratio of 1:0.4, and 2 drops of water was added to help initiate microwave carbonization process. An undoped carbonized sample of used CF (CCF) was prepared without APP. In this regard, CF along with 2 drops of water were placed into a boron nitride crucible, which was promptly situated in a foamed aluminum oxide box to contain the reaction. The box was subjected to microwave irradiation in a conventional microwave oven for $30 \mathrm{~min}$ at high power $(2.45 \mathrm{GHz}$ and 1.25 $\mathrm{kW}$ power) to carbonize the waste filters and then cooled to room temperature. Afterwards, the resulting products were powdered using a mortar and pestle and stored in a desiccator for later use.

\section{Physical characterization}

Physical characterization of CCF and DCCF were examined using various techniques. Scanning electron microscopy (SEM, JEOL JSM-7000F) was carried out to analyze the surface morphology of the bulk materials. For 
sample preparation to perform SEM imaging, doublesided carbon tape on aluminum mount substrate was used to hold carbon sample. Surface area and porosity analyzer (ASAP 2020 Micrometrics) with tandem Brunauer-Emmett-Teller (BET) method was used to determine surface area and pore characteristics of adsorbents using nitrogen gas $\left(\mathrm{N}_{2}\right)$ adsorption/desorption studies at $77 \mathrm{~K}$. X-ray photoelectron spectrometer (XPS, Thermo K-Alpha) was used to analyze surface elemental composition of dried carbonized samples. Fourier transform infrared (FTIR, Thermo Scientific Nicolet 6700) spectroscopy was conducted to confirm that $\mathrm{MB}$ was adsorbed onto adsorbent surface and not degraded during adsorption. Point of zero charge (PZC) was determined using a simple salt addition method in order to find the $\mathrm{pH}$ where adsorbent carries no net surface charge. Briefly, a suspension of adsorbent $(0.01 \mathrm{~g})$ was prepared in $0.1 \mathrm{M} \mathrm{NaNO}_{3}$ aqueous solution in different reaction vessels $\left(5 \mathrm{~g} \mathrm{~L}^{-1}\right.$ CCF or DCCF).

\section{Adsorption studies Adsorbent dosage}

To optimize the adsorbent dosage for adsorption, various masses $(5,7.5,10,15$, and $20 \mathrm{mg}$ ) were contacted with $50 \mathrm{~mL}$ of $20 \mathrm{ppm} \mathrm{MB}$ solution with $120 \mathrm{rpm}$ stirring speed. After reaching equilibrium $(24 \mathrm{~h})$, the treated MB solutions were centrifuged at $3800 \mathrm{rpm}$ for $10 \mathrm{~min}$ to remove the adsorbent from dye solution. Absorption spectrophotometry (Lambda $850 \mathrm{UV}$-Vis spectrophotometer with $1 \mathrm{~cm}$ path length quartz cuvette at $665 \mathrm{~nm}$ wavelength) was utilized to determine the concentration of $\mathrm{MB}$ remaining in solution at equilibrium. From this, the percent removal and adsorption capacity were determined.

\section{Initial concentration}

Batch adsorption experiments were conducted to analyze the effects of $\mathrm{MB}$ concentration adsorb onto CCF and DCCF from CFs. From stock, $50 \mathrm{~mL} \mathrm{MB} \mathrm{solu-}$ tions of different concentration (5 to $100 \mathrm{ppm}$ ) were prepared. $10 \mathrm{mg}$ of adsorbent samples were placed into each MB solution. The solutions with adsorbent were stirred with a constant speed at room temperature until equilibrium was assumed $(24 \mathrm{~h})$. The equilibrium data were then fitted into Langmuir and Freundlich isotherm models to analyze the interactions between $\mathrm{MB}$ and CCF or DCCF.

\section{Adsorption kinetics}

To gain insight on how the mechanism of adsorption of $\mathrm{MB}$ onto CCF and DCCF is influenced by time, adsorption kinetic experiments were designed. Various initial concentrations of $\mathrm{MB}$ solution $(5-100 \mathrm{ppm})$ were prepared in $50 \mathrm{~mL}$ water, and each solution was contacted with a constant $10 \mathrm{mg}$ of adsorbent powder sample. These samples were stirred continuously. After specified time intervals, absorbance of an aliquot of the $\mathrm{MB}$ solution was analyzed by absorbance spectroscopy. This data was fitted using pseudo-first and second order modelling to ascertain the primary adsorption mechanism for the two adsorbent materials derived from CFs.

\section{Effect of temperature}

Solutions of $\mathrm{MB}$ were prepared at $30 \mathrm{ppm}$ and adjusted to various temperatures: $25,35,45$, and $55^{\circ} \mathrm{C}$. Then, 10 mg of adsorbent was added and stirred for $24 \mathrm{~h}$. Afterwards, remaining concentration of $\mathrm{MB}$ dye was analyzed via absorbance spectrophotometry, and adsorption capacity was calculated.

\section{Effect of $\mathrm{pH}$}

This experiment was designed by keeping the amount of adsorbent and the concentration of adsorbate (MB dye) constant while changing only the $\mathrm{pH}$ of the sample. Multiple solutions of $50 \mathrm{~mL}$ of $30 \mathrm{ppm} \mathrm{MB}$ of various $\mathrm{pH}$ were prepared by using dilute concentrations of $\mathrm{NaOH}$ and $\mathrm{HCl} .10 \mathrm{mg}$ of adsorbent was contacted in the aforementioned test solutions. The mixture was stirred at $120 \mathrm{rpm}$ until equilibrium was assumed (24 h) at different initial $\mathrm{pH}$.

\section{Reusability of adsorbents}

Reusability of adsorbents was determined by comparing $Q_{e}$ values after 4 cycles of washing and reuse of materials. Test solutions of $\mathrm{MB}$ were prepared at $20 \mathrm{ppm}(50$ $\mathrm{mL}$ ) to which $10 \mathrm{mg}$ CCF or DCCF were added and stirred $(120 \mathrm{rpm})$ at room temperature for $24 \mathrm{~h}$ at neutral $\mathrm{pH}$. Afterwards, absorption was used to determine $\mathrm{Q}_{\mathrm{e}}$ value. Adsorbents were recovered using centrifugation and washed with $10 \mathrm{~mL}$ ethanol a total of three times. Then, the adsorbent was dried in oven at $70{ }^{\circ} \mathrm{C}$ for $1 \mathrm{~h}$. This was repeated over a total of 4 cycles.

\section{Results and discussion \\ Physical characterization \\ SEM}

SEM imaging was performed on adsorbent materials to analyze their surface morphologies. SEM image of CCF exhibits a rigid amorphous structure with smaller microstructures decorated on the surface (Fig. 1a). Imaging of DCCF sample displays cave-like structures and ridges at the macrostructure with spherical microscale structures distributed throughout (Fig. 1b). The doped sample also exhibited more sponge-like morphology indicating possession of a more well-formed pore structure than the undoped adsorbent. In order to confirm this, surface area analysis by BET was also performed. 


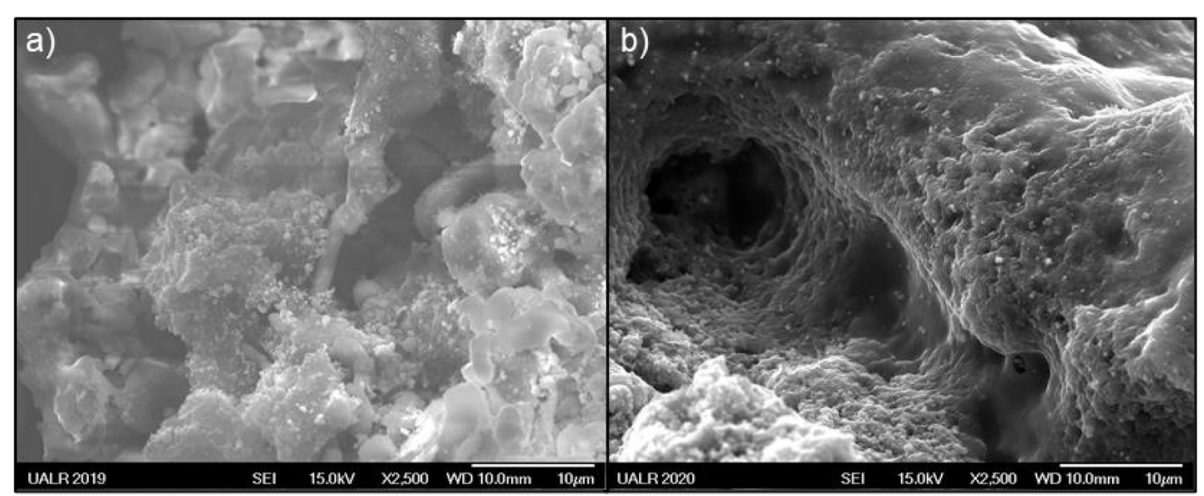

Fig. 1 a CCF and b DCCF adsorbents SEM images at 2500 X magnification

\section{BET surface area analysis}

Both adsorbents were characterized by BET in order to gain insight into their surface area and porosity. From adsorption-desorption isotherms, both adsorbents exhibit a type IV isotherm characterized by Langmuir-like behavior at relative low pressure and hysteresis loop at higher pressure (Fig. 2) [24]. The hysteresis loop is formed by capillary condensation in the mesoporous structures of the material. The BET surface area of CCF and DCCF adsorbents are 176 and $177 \mathrm{~m}^{2} \mathrm{~g}^{-1}$, respectively. The microwave activation process causes the formation of reducing gases leading to high surface area carbon materials. This result indicates that doping with APP does not play a significant role in altering the overall surface area of the activated material. However, DCCF is significantly more mesoporous (88\% mesopores by volume). This could be due to larger reducing gas formation when combined with APP. The overall results of BET analysis are tabulated in Table 1.

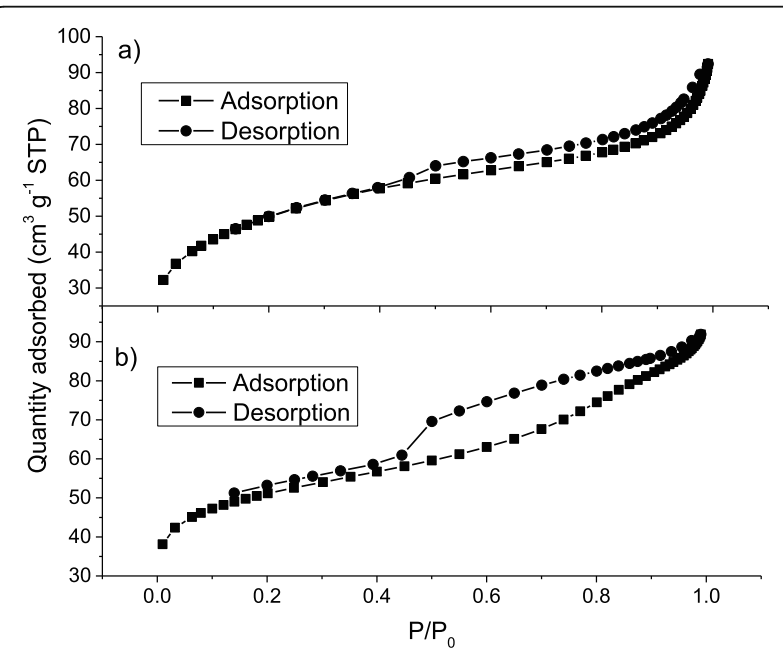

Fig. 2 Adsorption and desorption curves of $\mathbf{a}$ CCF and $\mathbf{b}$ DCCF

\section{XPS}

In order to determine surface elemental composition of adsorbent materials, XPS was performed. Various functional groups of atoms at the surface can greatly enhance adsorption mechanism by allowing chemisorption processes to occur. Survey scan spectra of both samples reveal the presence of carbon, oxygen, and phosphorus at the surface (Fig. 3). Results of CCF reveals the additional presence of silicon at a low percentage $(1.13 \%$, Table 2$)$. This is expected, as silicates can be formed in cigarette smoke and deposited in the filter during smoking [25]. DCCF contains much greater amount of phosphorus (3.98\%) and nitrogen at the surface, confirming that the doping of the material was successful. Nitrogen and phosphorus at the surface of adsorbent can aid in binding $\mathrm{MB}$ by altering the surface chemistry such as polarity and acid/base properties as well as introducing functional groups that can interact with $\mathrm{MB}$ in solution $[9,14]$.

\section{PZC}

The PZC of the adsorbents is analyzed in order to gain a deeper understanding of the possible adsorption mechanism onto the materials. The PZC can be defined as the $\mathrm{pH}$ where the net charge of an adsorbent is zero. $\mathrm{MB}$ is a cationic dye, and thus adsorption is favored when the solution $\mathrm{pH}$ is greater than the $\mathrm{PZC}$ of an adsorbent (adsorbent carries net negative charge). In order to determine PZC, a salt addition method was used as described previously [15]. A plot of $\Delta \mathrm{pH}$ versus $\mathrm{pH}_{\text {initial }}$ was formed where $\Delta \mathrm{pH}=0$ was deemed to be the PZC (Fig. 4). The PZC of CCF and DCCF were found to be 7.25 and 3.23, respectively. This implies that MB adsorption will be more favorable onto the doped adsorbent (DCCF) at a wider range of $\mathrm{pH}$.

FTIR

In order to confirm that $\mathrm{MB}$ was adsorbed onto DCCF and not degraded during adsorption process, 
Table 1 Surface area characteristics from BET

\begin{tabular}{llllll}
\hline Sample & $\begin{array}{l}\text { BET surface area }\left(\mathbf{m}^{\mathbf{2}}\right. \\
\left.\mathbf{g}^{-\mathbf{1}}\right)\end{array}$ & $\begin{array}{l}\text { Pore volume }\left(\mathbf{c m}^{\mathbf{3}}\right. \\
\left.\mathbf{g}^{-\mathbf{1}}\right)\end{array}$ & $\begin{array}{l}\text { Micropore volume }\left(\mathbf{c m}^{\mathbf{3}}\right. \\
\left.\mathbf{g}^{-\mathbf{1}}\right)\end{array}$ & $\begin{array}{l}\text { Mesopore volume }\left(\mathbf{c m}^{\mathbf{3}}\right. \\
\left.\mathbf{g}^{-\mathbf{1}}\right)\end{array}$ & $\begin{array}{l}\text { Average pore width } \\
(\AA)\end{array}$ \\
\hline CCF & 176 & 0.140 & 0.042 & 0.098 & 31.7 \\
DCCF & 177 & 0.137 & 0.017 & 0.120 & 31.1 \\
\hline
\end{tabular}

FTIR was used to identify characteristic carbon-sulfur bonds post-adsorption onto DCCF. Compared to the raw adsorbent material, there are two additional peaks at 1191 and $1321 \mathrm{~cm}^{-1}$ which are correlated to the $\mathrm{C}=\mathrm{S}$ double bond and the $\mathrm{C}-\mathrm{S}$ bond, respectively (Fig. 5). The introduction of these carbon sulfur bonds post-adsorption confirms that MB is adsorbed to the surface and its structure is not altered during adsorption process. A similar band at $1396 \mathrm{~cm}^{-1}$ was observed for CCF post MB adsorption (Fig. S1 of Supplemental Materials), indicating a similar nondegradative adsorption process for the undoped sample as well.

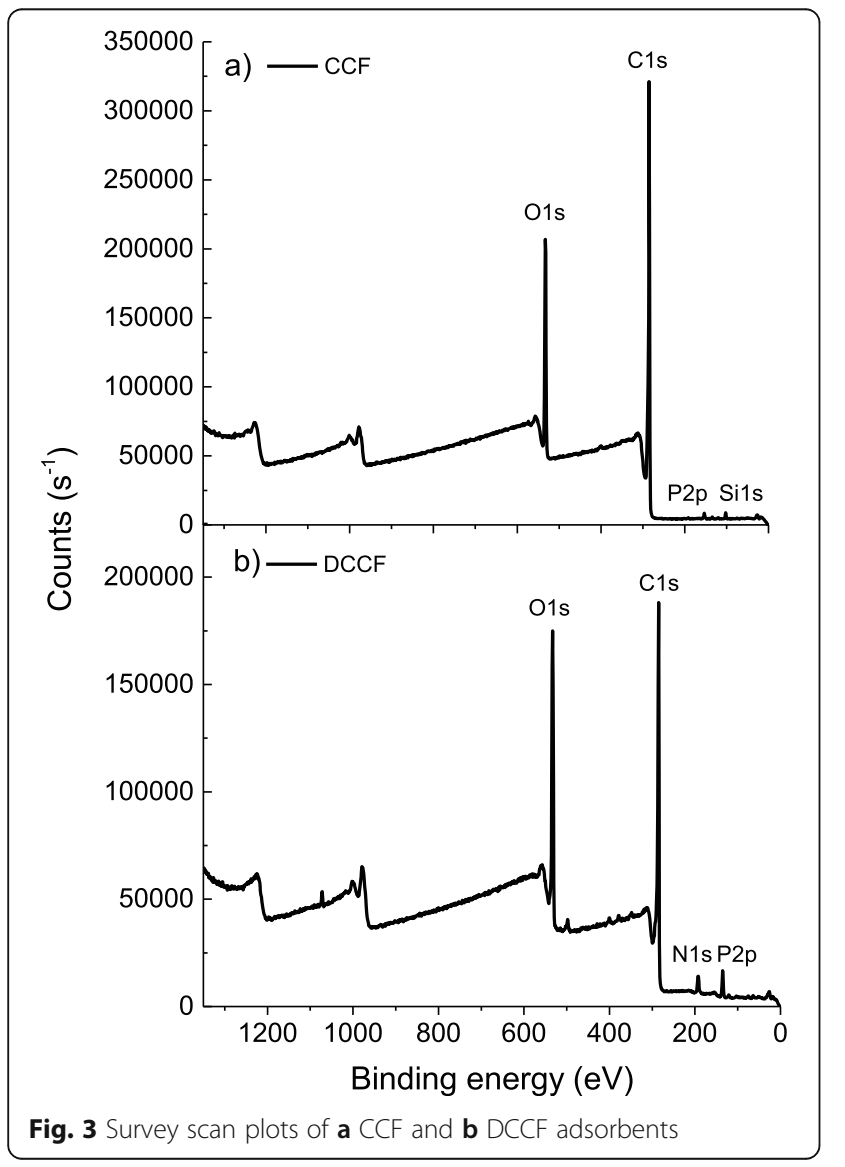

\section{Adsorption characterization \\ Adsorbent dosage}

Various masses of CCF or DCCF were contacted with $50 \mathrm{~mL}$ solutions of $\mathrm{MB}$ dye, separately, and allowed to reach equilibrium. Afterwards, the percent removal of dye was calculated using Eq. (1).

$$
\text { Percent Removal }=\left(\frac{C_{0}-C_{e}}{C_{0}}\right) * 100
$$

where $\mathrm{C}$ is the concentration of $\mathrm{MB}$ in solution initially and at equilibrium. The amount of dye adsorbed at equilibrium, $\mathrm{Q}_{\mathrm{e}}\left(\mathrm{mg} \mathrm{g}^{-1}\right)$ was determined with Eq. (2):

$$
Q_{e}=\frac{\left(C_{o}-C_{e}\right) V}{W}
$$

where $\mathrm{V}$ is the volume of solution and $\mathrm{W}$ is the weight of adsorbent. For both samples, percent removal of dye increases with an increase in adsorbent dosage (Fig. 6). However, $Q_{e}$ increases to a maximum value and then decreases after a certain mass dosage. For CCF, the maximum $Q_{e}$ value is obtained at a mass dosage of $10 \mathrm{mg}$. For DCCF, this occurs at a slightly lower mass of $7.5 \mathrm{mg}$. To keep conditions the same for both adsorbents, a mass loading of $10 \mathrm{mg}$ is used for further adsorption experiments.

\section{Effect of initial concentration}

The effect of initial concentration of $\mathrm{MB}$ adsorption onto the adsorbents was investigated by contacting a fixed mass of $10 \mathrm{mg}$ adsorbent to varying concentration of MB from 5 to $100 \mathrm{ppm}$. For both adsorbents, it was observed that the adsorption capacity increased as the initial concentration of MB increased (Fig. 7). This is due to the mass transfer driving force between liquidsolid interface involved in heterogeneous adsorption. More dye molecules in the liquid phase shifts

Table 2 Surface elemental composition (At\%) of adsorbents

\begin{tabular}{lll}
\hline Element & CCF & DCCF \\
\hline C1s & 80.77 & 72.56 \\
O1s & 17.8 & 21.91 \\
P2p & 0.30 & 3.98 \\
N1s & - & 0.90 \\
Si2p & 1.13 & - \\
\hline
\end{tabular}




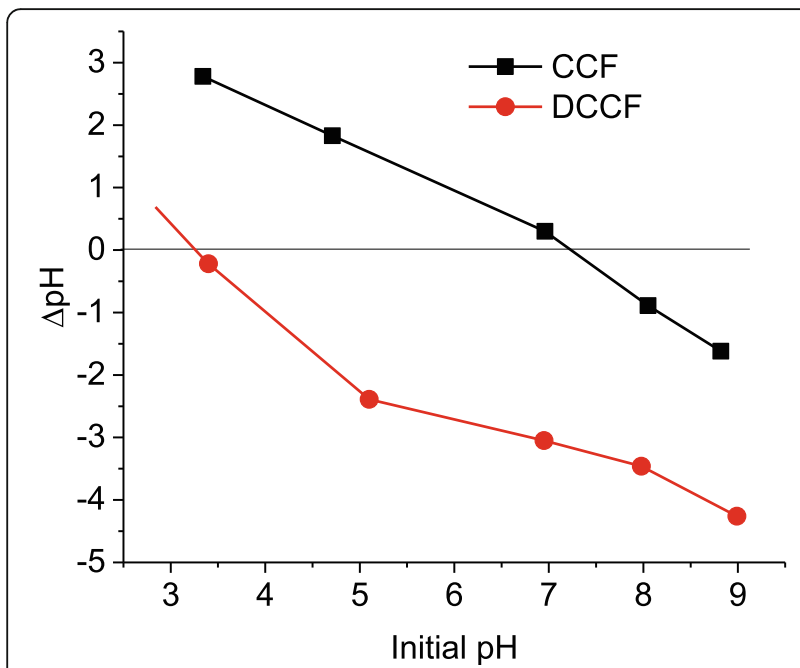

Fig. 4 Point of Zero Charge (PZC) plots for CCF and DCCF

equilibrium toward adsorption onto the solid phase. Also, when the initial concentration is very low (5 ppm), both adsorbents exhibit a similar $\mathrm{Q}_{\mathrm{e}}$ value. However, for $\mathrm{CCF}$, the maximum experimental $\mathrm{Q}_{\mathrm{e}}$ value achieved is $195 \mathrm{mg} \mathrm{g}^{-1}$ while DCCF reaches a value of $294 \mathrm{mg} \mathrm{g}^{-1}$. This indicates the enhanced adsorptive capabilities of DCCF compared to CCF.

\section{Adsorption isotherms}

Adsorption isothermal modelling of the data allows a detailed investigation of possible adsorption mechanisms. The models help to describe the interactions between adsorbent and dissolved dye species at the liquid-solid phase boundary and allow an estimation of the maximum adsorption capacity. The two most common

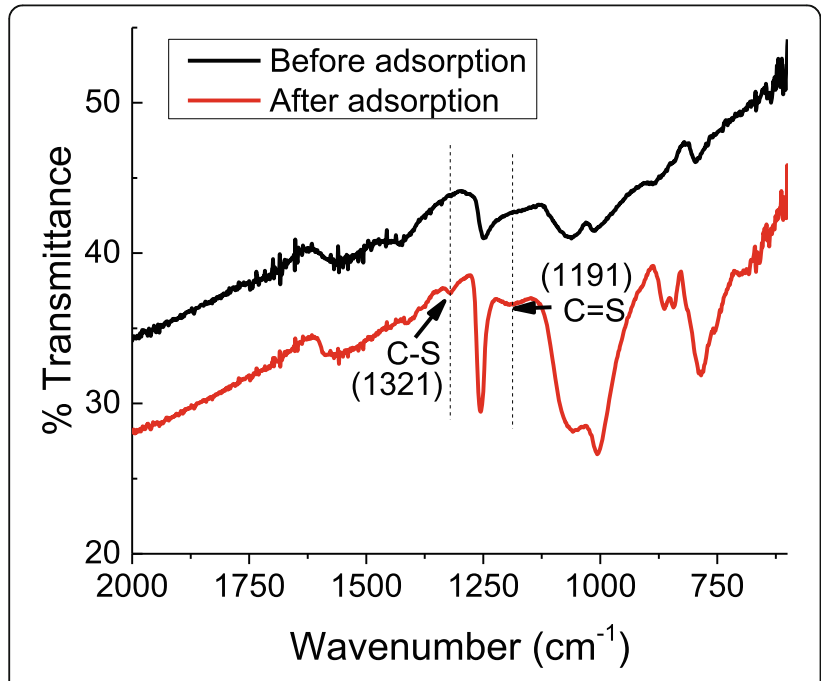

Fig. 5 FTIR of DCCF adsorbent before and after adsorption of MB

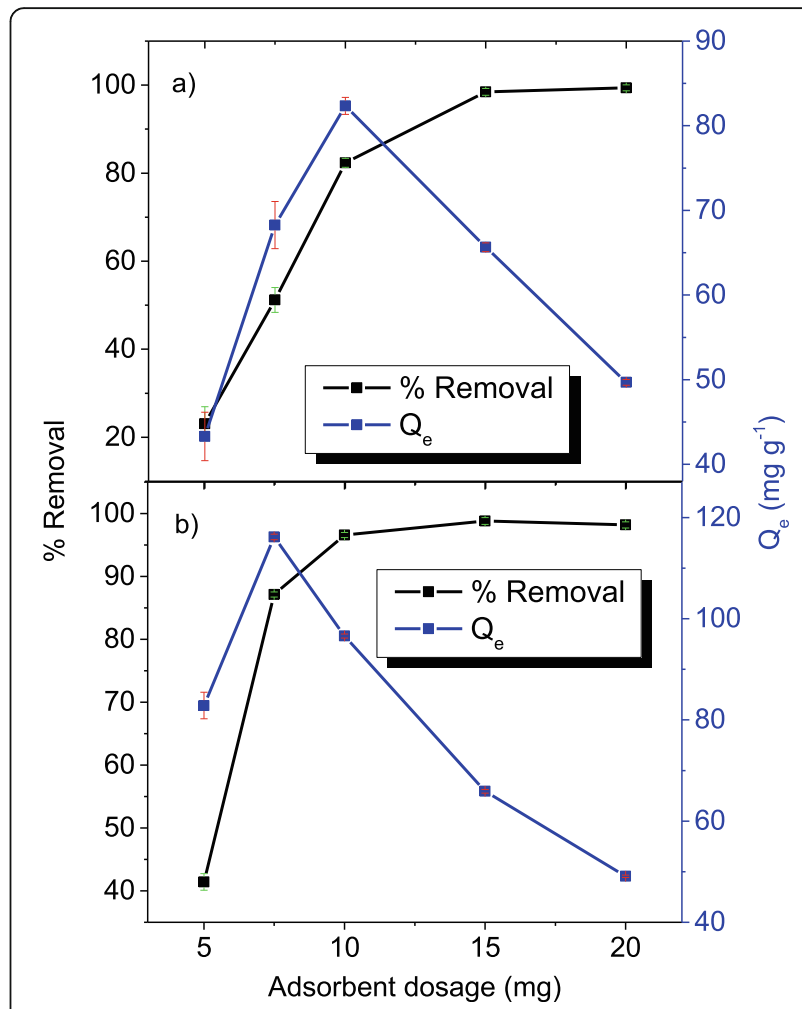

Fig. 6 Effects of adsorbent dosage on adsorption capacities and \% MB removal for $\mathbf{a}$ CCF and $\mathbf{b}$ DCCF

models, Langmuir and Freundlich, were applied to the adsorption data of CCF and DCCF samples.

Modelling with the Langmuir equation is performed with several assumptions, one being that only a single layer of adsorbate can be adsorbed onto the active sites of an adsorbent, and there is a limited amount of those sites. Langmuir model also makes the assumptions that

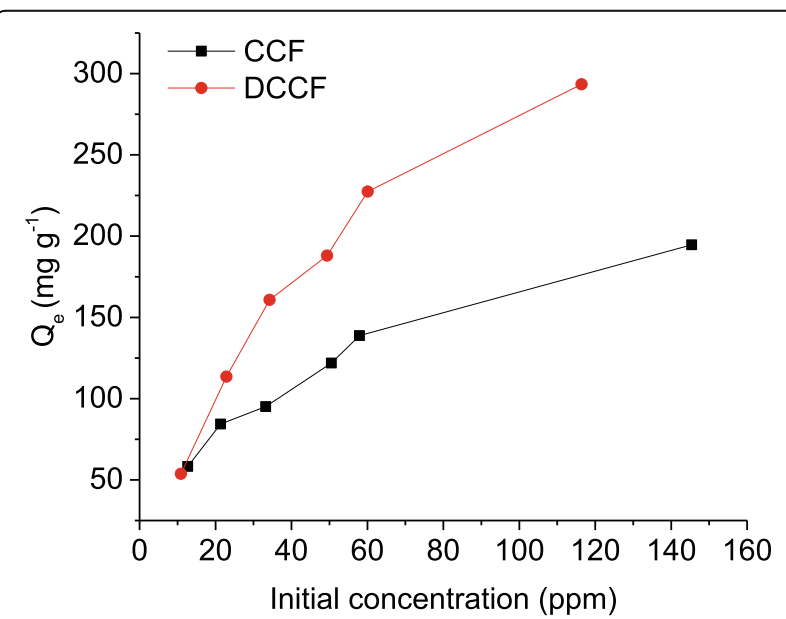

Fig. 7 Effects of initial MB concentration on the equilibrium adsorption capacity of CCF and DCCF 
those active sites are energetically equivalent regardless of their occupation, meaning the Langmuir equation does not consider repulsive forces of molecules bound to adsorbent surface. The linear form of the Langmuir equation [26], Eq. (3), was used to determine the Langmuir constants related to the maximum adsorption amount $\left(\mathrm{Q}_{\max }\right)$ and the adsorption energy $\left(\mathrm{K}_{\mathrm{L}}\right)$.

$$
\frac{C_{e}}{Q_{e}}=\frac{1}{Q_{\max } K_{L}}+\frac{1}{Q_{\max }} C_{e}
$$

From the slope of Eq. (3), $\mathrm{Q}_{\max }$ can be obtained and was determined to be 213 and $303 \mathrm{mg} \mathrm{g}^{-1}$ for CCF and DCCF, respectively (Table 3). This indicates that DCCF possesses a higher capacity to adsorb MB from solution. The $\mathrm{K}_{\mathrm{L}}$ value of DCCF is also much higher than CCF (0.38 vs 0.08$)$ indicating a stronger interaction between doped sample surface and the adsorbate. Both models showed reasonable fitting with $\mathrm{R}^{2}$ values of 0.911 and 0.986 for CCF and DCCF, respectively.

Modelling with the Freundlich equation is done with the assumptions of heterogeneous adsorbent surfaces and that the adsorption sites have varying energy. The Freundlich equation, Eq. (4), was also used in the linear form:

$$
\log Q_{e}=\log K_{F}+\frac{1}{n} \log C_{e}
$$

where $K_{F}$ is a constant related to adsorption capacity and $\mathrm{n}$ is a constant related to adsorption intensity. Neither adsorbent was well represented by the model with $\mathrm{R}^{2}$ values less than 0.88 in both cases. However, both adsorbents possess an $\mathrm{n}$ value greater than 1 which is indicative of a favorable process of adsorption. The $\mathrm{n}$ value of DCCF is greater than that of CCF (Table 3) which can be correlated to stronger interactions between adsorbate and the adsorbent material due to greater amount of nitrogen and phosphorus at the surface. $\mathrm{K}_{\mathrm{F}}$ values are related to adsorption capacity and, like Langmuir modelling of the data, DCCF exhibits a higher $\mathrm{K}_{\mathrm{F}}$

Table 3 Langmuir and Freundlich constant value results from linear fitting and free energy values for CCF and DCCF

\begin{tabular}{llll}
\hline Isotherm & Parameter & CCF & DCCF \\
\hline Langmuir & $\mathrm{Q}_{\max }\left(\mathrm{mg} \mathrm{g}^{-1}\right)$ & 213 & 303 \\
& $\mathrm{~K}_{\mathrm{L}}\left(\mathrm{L} \mathrm{mg}^{-1}\right)$ & 0.08 & 0.38 \\
& $\mathrm{R}^{2}$ & 0.911 & 0.986 \\
Freundlich & $\mathrm{K}_{\mathrm{F}}\left(\mathrm{mg} \mathrm{g}^{-1}\left(\mathrm{~L} \mathrm{mg}^{-1}\right) 1 \mathrm{n}^{-1}\right)$ & 54 & 121 \\
& $\mathrm{n}$ & 3.85 & 4.55 \\
& $\mathrm{R}^{2}$ & 0.874 & 0.828 \\
Gibb's free energy & $\Delta \mathrm{G}^{\circ}\left(\mathrm{KJ} \mathrm{mol}^{-1}\right)$ & -5.8 & -11.1 \\
\hline
\end{tabular}

value. Langmuir and Freundlich fitting plots are displayed in Fig. S2.

To determine the spontaneity of the adsorption process of CCF and DCCF, Gibbs free energy was calculated from Eq. (5).

$$
\Delta G^{o}=-R T \ln k_{0}
$$

where $\mathrm{R}$ is the gas constant, $\left(8.314 \mathrm{~J} \mathrm{~mol}^{-1} \mathrm{~K}^{-1}\right) \mathrm{T}$ is the temperature $(298 \mathrm{~K})$, and $\mathrm{k}_{0}$ is equal to $\mathrm{Q}_{\mathrm{e}} / \mathrm{C}_{\mathrm{e}}$ [27]. Both CCF and DCCF exhibited spontaneous adsorption, due to negative calculated values of $\Delta G^{\circ}$. The value of $\Delta G^{\circ}$ for DCCF is more negative than for CCF (Table 3) which indicates that the doped CF material shows more highly spontaneous adsorption at $298 \mathrm{~K}$.

\section{Kinetics}

To investigate the kinetic mechanism of adsorbents, kinetic adsorption was fitted into pseudo-first and pseudosecond order kinetic models. Experiments were performed by varying initial concentration from 5 to 100 ppm of $\mathrm{MB}$ at natural $\mathrm{pH}$ and recording the dye concentration at various time intervals after contact with adsorbent (Fig. 8a and b). The pseudo-first order model was used in the linear form, Eq. (6), in order to evaluate the first order rate constant, $\mathrm{k}_{1}$.

$$
\log \left(Q_{e}-Q_{t}\right)=\log Q_{e}-\frac{k_{1}}{2.303} t
$$

where $Q_{t}$ is the amount of dye adsorbed at time, $t . R^{2}$ values were used to determine the better fitting model. The pseudo-second order equation was also used in the linear form, Eq. (7), to determine second order rate constant, $\mathrm{k}_{2}$.

$$
\frac{t}{Q_{t}}=\frac{1}{k_{2} Q_{e}^{2}}+\frac{1}{Q_{e}} \mathrm{t}
$$

Plotting the linear form of Eq. 6 and 7 generates a straight line in which $\mathrm{k}$ can be directly calculated (Fig. 8c, Fig. 8 d, and Fig. S3). CCF average $\mathrm{R}^{2}$ value is 0.88 (Table S1) while the average value of $\mathrm{R}^{2}$ for second order fitting is 0.99 . This indicates a better fitting of CCF adsorption to pseudo-second order kinetics. DCCF average $\mathrm{R}^{2}$ value for pseudo-first order plot is 0.90 while for pseudo-second, the value average is 0.99 . This indicates that the adsorption mechanism is better correlated to a pseudo-second order process for both samples. This process is characterized by strong chemisorptive adsorption between $\mathrm{MB}$ and $\mathrm{CCF}$ and DCCF adsorbents. This mechanism involves the chemical binding between functional groups on the surface of adsorbent and MB dye. The enhancement of nitrogen, phosphorus, and oxygen elemental composition at the surface of DCCF is 

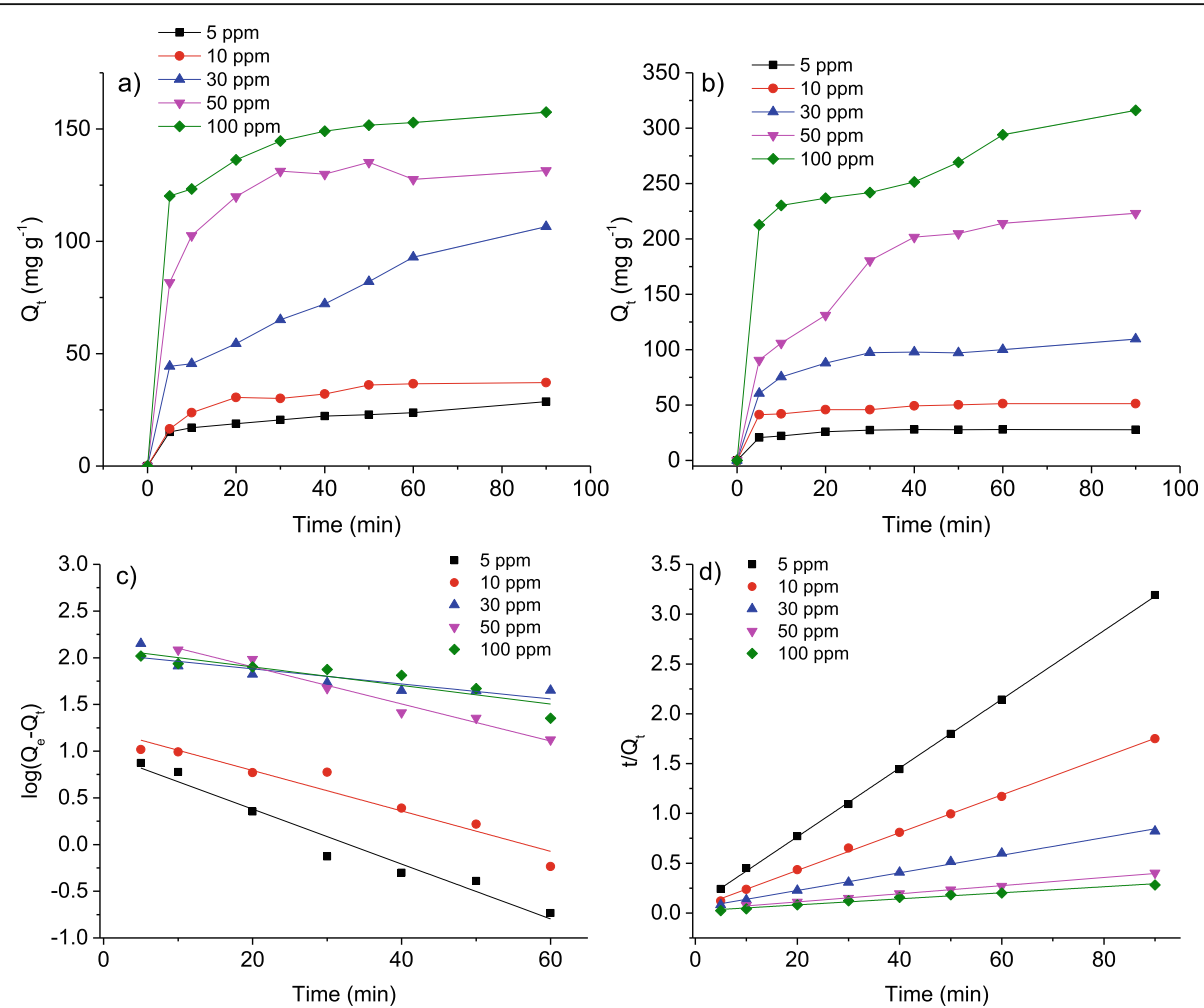

Fig. 8 Kinetics plot of a CCF and $\mathbf{b}$ DCCF and pseudo $\mathbf{c}$ first and $\mathbf{d}$ second order fitting of data of doped sample

attributed to enhancing chemisorptive active sites. Moreover, improved diffusion of MB into the mesoporous structure of the adsorbents can aid to enhance their adsorption performance.

In addition to kinetic modelling, the standard deviation was calculated from Eq. (8):

$$
\Delta Q(\%)=100 \times \sqrt{\frac{\sum\left[\frac{Q_{t, e x p}-Q_{t, c a l}}{Q_{t, e x p}}\right]^{2}}{n-1}}
$$

For CCF adsorption, $\Delta Q$ was found to be between 1 and 9 for second order compared to 7-20 for first order
(Table S1). Similarly, DCCF displayed $\Delta Q$ values between 5 and 17 for pseudo-first order and 5-8 for pseudo-second order. This data further supports a chemisorptive mechanism of adsorption for the two adsorbents.

The adsorption capacity of CCF and DCCF were compared to those of other waste-derived carbon materials for their removal of MB from solution. The waste precursors and corresponding maximum adsorption capacities are reported in Table 4. From this data, it can be concluded that CCF and DCCF show exceptional application as adsorbents for the removal of cationic MB dye as their adsorption capacities are higher than many other

Table 4 Comparison of maximum adsorption capacity of MB of CCF and DCCF to other adsorbent materials (at $298 \mathrm{~K}$ )

\begin{tabular}{|c|c|c|}
\hline Adsorbent precursor & Maximum capacity $\left(\mathrm{mg} \mathrm{g}^{-1}\right)$ & Reference \\
\hline Carbonized cigarette filter (CCF) & 212.8 & This work \\
\hline$P$ and $N$ co-doped cigarette filter (DCCF) & 303.0 & This work \\
\hline Banana peel & 227.2 & {$[28]$} \\
\hline Commercial activated carbon & 199.6 & [29] \\
\hline Coffee grounds & 181.8 & [30] \\
\hline Coconut leaves & 66.0 & [31] \\
\hline Sludge & 46.7 & {$[32]$} \\
\hline Rice husk & 33.9 & [33] \\
\hline Seed pod & 14.8 & [34] \\
\hline
\end{tabular}


waste-derived carbons. Additionally, many of the previously used waste precursors require chemical activation, whereas this work highlights a simplistic method to produce doped carbons with desirable adsorption characteristics.

\section{Effect of temperature}

In order to evaluate the temperature effect on adsorption onto the cigarette-based samples, experiments were performed at four different temperatures ranging from 25 to $55^{\circ} \mathrm{C}$. It is observed that for both adsorbent materials, the adsorption capacity, $\mathrm{Q}_{\mathrm{e}}$ is increasing as the temperature increases (Fig. 9). This is due to an increased diffusion rate of $\mathrm{MB}$ molecules into the internal cavities of porous carbons [26]. This occurs mainly due to the lowering of viscosity of the solvent as temperature increases. This is also indicative of an endothermic adsorption process for both adsorbents [35].

\section{Effect of $p H$}

The effect of solution $\mathrm{pH}$ on MB's adsorption was analyzed by contacting $10 \mathrm{mg}$ of adsorbent to $50 \mathrm{~mL}$ of 30 ppm MB solution (Fig. 10). CCF adsorption is greatly dependent on $\mathrm{pH}$, ranging from 78 to $100 \mathrm{mgg}^{-1}$ in a $\mathrm{pH}$ range from 3.9 to 10.2 . This is due to the neutral PZC of CCF. Below pH 7, the adsorption is unfavored because of the repulsive forces between $\mathrm{MB}$ and the positive adsorbent surface. In contrast, DCCF adsorption capacity remains relatively unchanged over the $\mathrm{pH}$ range 3.4 to 10.9. This is because of a low value of PZC value of DCCF, causing it to have a net negative surface charge at $\mathrm{pH}$ past 3.2 .

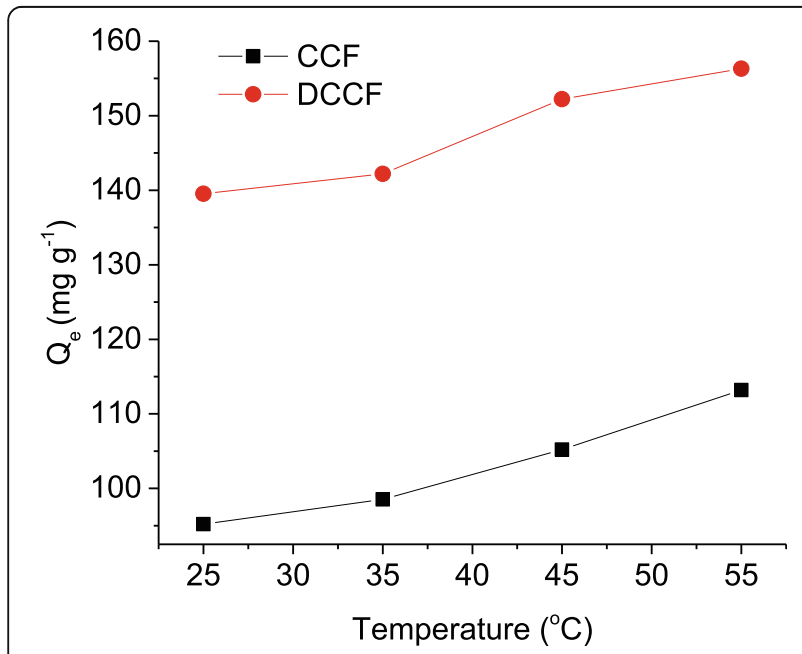

Fig. 9 Effect of temperature on equilibrium adsorbent capacity from initial concentration of $30 \mathrm{ppm}$ and $10 \mathrm{mg}$ adsorbent dosage

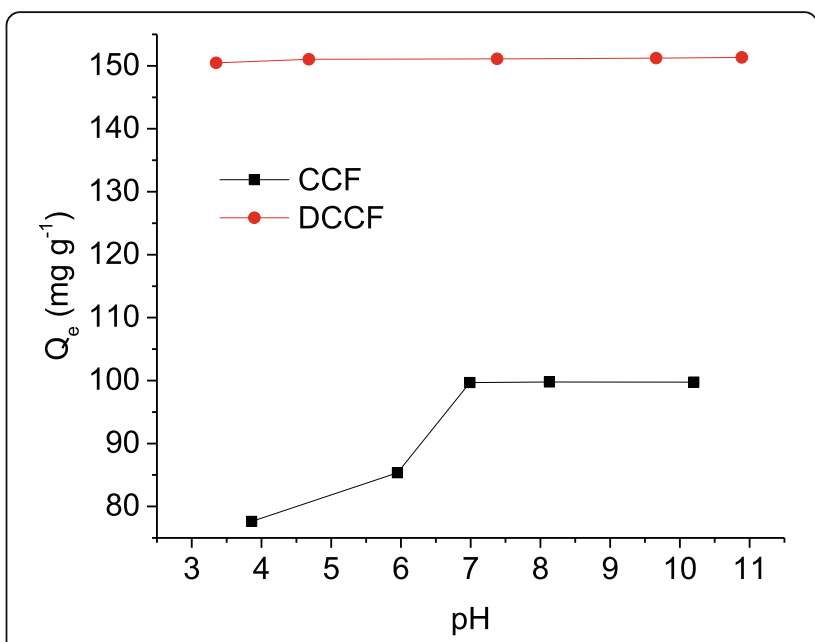

Fig. 10 Effect of initial solution $\mathrm{pH}$ on adsorption capacity of CCF and DCCF using an initial $50 \mathrm{~mL}$ of $30 \mathrm{ppm} \mathrm{MB}$ solution

\section{Reusability of adsorbents}

Reusability of adsorbents was determined in order to assess the long-term utility of CCF and DCCF. This was carried out using adsorption-desorption experiment where $\mathrm{MB}$ was adsorbed onto the adsorbent and desorbed with ethanol thrice prior to reuse. This experiment was performed for a total of 4 cycles where $Q_{e}$ was calculated for each cycle. It was found that both adsorbents retain their adsorption characteristics up to the second cycle after which the $Q_{e}$ begins to decrease at a faster rate (Fig. S4). This decrease in $\mathrm{Q}_{\mathrm{e}}$ value is attributed to the reduction of active sites at the adsorbent surface during desorption of MB [36]. Thus, both CCF and DCCF have potential to be used over several times before being discarded.

\section{Conclusions}

Useful adsorbent materials were successfully prepared from waste CCF using a simple and rapid one-step microwave synthesis. DCCF exhibited an exceptional maximum adsorption value of $303 \mathrm{mg} \mathrm{g}^{-1}$, making it a highly efficient and cost efficient adsorbent for MB removal. The materials were characterized in detail to reveal crucial information about their surface area, elemental composition, and morphology. The adsorbents were shown to have exceptional surface area $\left(\sim 177 \mathrm{~m}^{2}\right.$ $\mathrm{g}^{-1}$ ) and well-developed porosity. Doping of the sample was confirmed using XPS which showed significant contribution of phosphorus and nitrogen on the surface of the material which played a significant role in enhancing the adsorption capacity of the material. Adsorption of $\mathrm{MB}$ onto adsorbents was found to be best correlated to a monolayer adsorption process as confirmed by higher $\mathrm{R}^{2}$ value with Langmuir fitting. Further, the adsorbents undergo a pseudo-second order adsorption process 
which is indicative of a chemisorptive process. Adsorption onto the adsorbents is spontaneous $(\Delta G<0)$ and endothermic in nature and can be recycled several times efficicently before being discarded. This work highlights an inexpensive and green method to convert a common litter source into a useful material for water remediation.

\section{Supplementary Information}

The online version contains supplementary material available at https://doi. org/10.1186/s42834-021-00108-5.

\section{Additional file 1 .}

\section{Acknowledgements}

The authors acknowledge Center for Integrative Nanotechnology Sciences for characterization instrumentation.

\section{Authors' contributions}

Samantha Macchi, Zane Alsebai, Arooba Ilyas, and Shiraz Atif collected adsorption data and performed data analysis. Samantha Macchi and Fumiya Watanabe collected physical characterization data. Tito Viswanathan and Noureen Siraj provided supervision, project administration, and acquisition of funding. Writing and original draft preparation was conducted by Samantha Macchi, Zane Alsebai and Noureen Siraj. All authors read and approved the final manuscript.

\section{Funding}

This research acknowledges the Signature award funding and startup funds from the University of Arkansas at Little Rock.

\section{Availability of data and materials}

The datasets generated during and/or analyzed during the current study are available from the corresponding author on reasonable request.

\section{Declarations}

\section{Competing interests}

The authors declare they have no competing interests.

\section{Author details}

${ }^{1}$ Department of Chemistry, University of Arkansas, Little Rock 72204, USA. ${ }^{2}$ Little Rock Central High School, Little Rock 72202, USA. ${ }^{3}$ Center for Integrative Nanotechnology Sciences, University of Arkansas, Little Rock 72204, USA.

Received: 7 May 2021 Accepted: 6 September 2021

Published online: 28 October 2021

\section{References}

1. Greer B, Maul R, Campbell K, Elliott C. Detection of freshwater cyanotoxins and measurement of masked microcystins in tilapia from Southeast Asian aquaculture farms. Anal Bioanal Chem 2017:409:4057-69.

2. Lellis B, Favaro-Polonio CZ, Pamphile JA, Polonio JC. Effects of textile dyes on health and the environment and bioremediation potential of living organisms. Biotechnol Res Innov 2019;3:275-90.

3. Demissie H, An GY, Jiao RY, Ritigala T, Lu S, Wang DS. Modification of high content nanocluster-based coagulation for rapid removal of dye from water and the mechanism. Sep Purif Technol 2021;259:117845.

4. Katheresan V, Kansedo J, Lau SY. Efficiency of various recent wastewater dye removal methods: a review. J Environ Chem Eng 2018:6:4676-97.

5. Ali I, Asim M, Khan TA. Low cost adsorbents for the removal of organic pollutants from wastewater. J Environ Manage 2012;113:170-83.

6. Sikdar D, Goswami S, Das P. Activated carbonaceous materials from tea waste and its removal capacity of indigo carmine present in solution: synthesis, batch and optimization study. Sustain Environ Res 2020;30:30.

7. Liang BL, Li KX, Liu Y, Kang XW. Nitrogen and phosphorus dual-doped carbon derived from chitosan: an excellent cathode catalyst in microbial fuel cell. Chem Eng J 2019;358:1002-11.
8. Sharifzade G, Asghari A, Rajabi M. Highly effective adsorption of xanthene dyes (rhodamine $B$ and erythrosine $B$ ) from aqueous solutions onto lemon citrus peel active carbon: characterization, resolving analysis, optimization and mechanistic studies. RSC Adv 2017:7:5362-71.

9. Li H, An NH, Liu G, Li JL, Liu N, Jia MJ, et al. Adsorption behaviors of methyl orange dye on nitrogen-doped mesoporous carbon materials. J Colloid Interf Sci 2016;466:343-51.

10. Lian F, Cui GN, Liu ZQ, Duo L, Zhang GL, Xing BS. One-step synthesis of a novel $\mathrm{N}$-doped microporous biochar derived from crop straws with high dye adsorption capacity. J Environ Manage 2016;176:61-8.

11. Wang ZW, Wang K, Wang YH, Wang SM, Chen ZM, Chen JF, et al. Largescale fabrication of $\mathrm{N}$-doped porous carbon nanosheets for dye adsorption and supercapacitor applications. Nanoscale 2019;11:8785-97.

12. Silva TL, Cazetta AL, Souza PSC, Zhang T, Asefa T, Almeida VC. Mesoporous activated carbon fibers synthesized from denim fabric waste: efficient adsorbents for removal of textile dye from aqueous solutions. J Clean Prod 2018:171:482-90.

13. Vigneshwaran S, Sirajudheen P, Karthikeyan P, Meenakshi S. Fabrication of sulfur-doped biochar derived from tapioca peel waste with superior adsorption performance for the removal of Malachite green and Rhodamine B dyes. Surf Interfaces 2021;23:100920.

14. Suo FY, You XW, Ma YQ, Li YQ. Rapid removal of triazine pesticides by $P$ doped biochar and the adsorption mechanism. Chemosphere 2019:235: 918-25.

15. Macchi S, Siraj N, Viswanathan T. Kinetic and mechanistic study of dye sorption onto renewable resource-based doped carbon prepared by a microwave-assisted method. Environ Technol 2020:1-10.

16. Roldan L, Marco Y, Garcia-Bordeje E. Bio-sourced mesoporous carbon doped with heteroatoms $(\mathrm{N}, \mathrm{S})$ synthesised using one-step hydrothermal process for water remediation. Micropor Mesopor Mat 2016:222:55-62.

17. Qamar W, Abdelgalil AA, Aljarboa S, Alhuzani M, Altamimi MA. Cigarette waste: assessment of hazard to the environment and health in Riyadh city. Saudi J Biol Sci 2020;27:1380-3

18. Puls J, Wilson SA, Holter D. Degradation of cellulose acetate-based materials: a review. J Polym Environ 2011;19:152-65.

19. Moerman JW, Potts GE. Analysis of metals leached from smoked cigarette litter. Tob Control 2011;20:30-5

20. Xiong QC, Bai QH, Li C, Li DL, Miao XJ, Shen YH, et al. Nitrogen-doped hierarchical porous carbons from used cigarette filters for supercapacitors. J Taiwan Inst Chem E 2019;95:315-23.

21. Lee M, Kim GP, Song HD, Park S, Yi J. Preparation of energy storage material derived from a used cigarette filter for a supercapacitor electrode. Nanotechnology 2014;25:345601.

22. Kim GP, Lee M, Song HD, Bae S, Yi J. Highly efficient supporting material derived from used cigarette filter for oxygen reduction reaction. Catal Commun 2016:78:1-6

23. Macchi S, Siraj N, Watanabe F, Viswanathan T. Renewable-resourcebased waste materials for supercapacitor application. Chemistry Select 2019:4:492-501.

24. Sing KSW, Everett DH, Haul RAW, Moscou L, Pierotti RA, Rouquerol J, et al. Reporting physisorption data for gas/solid systems with special reference to the determination of surface area and porosity. Pure Appl Chem 1985;57: 603-19.

25. Pappas RS. Toxic elements in tobacco and in cigarette smoke: inflammation and sensitization. Metallomics 2011:3:1181-98.

26. Nasuha N, Hameed BH, Din ATM. Rejected tea as a potential low-cost adsorbent for the removal of methylene blue. J Hazard Mater 2010;175: 126-32.

27. Archin S, Sharifi SH, Asadpour G. Optimization and modeling of simultaneous ultrasound-assisted adsorption of binary dyes using activated carbon from tobacco residues: response surface methodology. J Clean Prod 2019:239:118136.

28. Danish M, Ahmad T, Majeed S, Ahmad M, Lou ZY, Zhou P, et al. Use of banana trunk waste as activated carbon in scavenging methylene blue dye: kinetic, thermodynamic, and isotherm studies. Bioresour Technol Reports 2018:3:127-37.

29. Djilani C, Zaghdoudi R, Djazi F, Bouchekima B, Lallam A, Modarressi A, et al. Adsorption of dyes on activated carbon prepared from apricot stones and commercial activated carbon. J Taiwan Inst Chem E 2015;53:112-21.

30. Reffas A, Bernardet V, David B, Reinert L, Lehocine MB, Dubois M, et al. Carbons prepared from coffee grounds by $\mathrm{H}_{3} \mathrm{PO}_{4}$ activation: 
characterization and adsorption of methylene blue and Nylosan Red N2RBL. J Hazard Mater 2010;175:779-88.

31. Rashid RA, Jawad AH, Ishak MABM, Kasim NN. FeCl 3 -activated carbon developed from coconut leaves: characterization and application for methylene blue removal. Sains Malays 2018;47:603-10.

32. Hu WR, Xie Y, Lu S, Li PY, Xie TH, Zhang YK, et al. One-step synthesis of nitrogen-doped sludge carbon as a bifunctional material for the adsorption and catalytic oxidation of organic pollutants. Sci Total Environ 2019;680:51-60.

33. Dorothy A, Mideen AS. Adsorption of methylene blue dye on activated carbon from rice husk. J Chem Pharm Res 2015;7:761-5.

34. Jasper EE, Ajibola VO, Onwuka JC. Nonlinear regression analysis of the sorption of crystal violet and methylene blue from aqueous solutions onto an agro-waste derived activated carbon. Appl Water Sci 2020;10:132.

35. Li ZC, Hanafy H, Zhang L, Sellaoui L, Netto MS, Oliveira MLS, et al. Adsorption of congo red and methylene blue dyes on an ashitaba waste and a walnut shell-based activated carbon from aqueous solutions: experiments, characterization and physical interpretations. Chem Eng J 2020:388:124263

36. Wijayanti TA, Ansori M. Application of modified green algae Nannochloropsis sp. as adsorbent in the simultaneous adsorption of Methylene Blue and $\mathrm{Cu}$ (II) cations in solution. Sustain Environ Res 2021;31:17.

\section{Publisher's Note}

Springer Nature remains neutral with regard to jurisdictional claims in published maps and institutional affiliations.

- fast, convenient online submission

- thorough peer review by experienced researchers in your field

- rapid publication on acceptance

- support for research data, including large and complex data types

- gold Open Access which fosters wider collaboration and increased citations

- maximum visibility for your research: over $100 \mathrm{M}$ website views per year

At BMC, research is always in progress.

Learn more biomedcentral.com/submissions 